Matheus Bevilacqua Campelo Pereira

O Positivismo Conceitual de Hans Kelsen e o Neojusnaturalismo Finissiano:

Um Debate em torno da Justiça

Dissertação DE MESTRAdo

DEPARTAMENTO DE DIREITO Programa de Pós-Graduação em Direito 


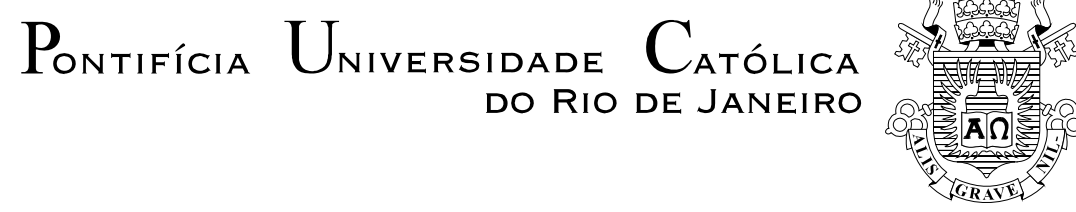

Matheus Bevilacqua Campelo Pereira

O Positivismo Conceitual de Hans Kelsen

e o Neojusnaturalismo Finissiano:

Um Debate em torno da Justiça

Dissertação apresentada ao Programa de PósGraduação em Direito da PUC-Rio como requisito parcial para obtenção do título de Mestre em Direito.

Orientador: Prof. Adrian Sgarbi

Rio de Janeiro

Setembro de 2010 


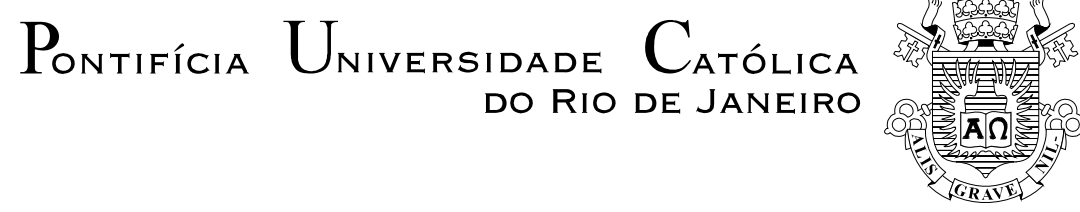

Matheus Bevilacqua Campelo Pereira

\section{O Positivismo Conceitual de Hans Kelsen \\ e o Neojusnaturalismo Finissiano: \\ Um Debate em torno da Justiça}

Dissertação apresentada como requisito parcial para obtenção do grau de Mestre pelo Programa de Pósgraduação em Direito da PUC-Rio. Aprovada pela Comissão Examinadora abaixo assinada.

Prof. Adrian Sgarbi
Orientador
Departamento de Direito - PUC Rio

Prof. Noel Struchiner Departamento de Direito - PUC Rio

Prof. Alejandro Bugallo Alvarez Departamento de Direito - PUC Rio

Prof. Mônica Herz Vice Decana de Pós-graduação do Centro de Ciências Sociais - PUC Rio

Rio de Janeiro, 05 de setembro de 2010 
Todos os direitos reservados. É proibida a reprodução total ou parcial do trabalho sem autorização da Universidade, do autor e do orientador.

\section{Matheus Bevilacqua Campelo Pereira}

Graduado em Direito na Faculdade de Direito Vianna Júnior, de Juiz de Fora, Minas Gerais, em 2003. Cursou pós graduação em Direito Tributário na Fundação Getúlio Vargas / MBA. Procurador autárquico municipal desde 2005. Advogado militante em Direito Previdenciário.

Ficha Catalográfica

Pereira, Matheus Bevilacqua Campelo

O positivismo conceitual de Hans Kelsen e o neojusnaturalismo finissiano: um debate em torno da justiça / Matheus Bevilacqua Campelo Pereira ; orientador: Adrian Sgarbi. - 2010.

$129 \mathrm{f.} \mathrm{;} 30 \mathrm{~cm}$

Dissertação (mestrado)-Pontifícia Universidade Católica do Rio de Janeiro, Departamento de Direito, 2010.

Inclui bibliografia

1. Direito - Teses. 2. Positivismo jurídico. 3. Direito natural. 4. Kelsen, Hans, 1881-1973. 5. Finnis, John. 6. Leis injustas. 7. Justiça. I. Sgarbi, Adrian. II. Pontifícia Universidade Católica do Rio de Janeiro. Departamento de Direito. III. Título. 
Para meus Pais Marcus e Eliane, pela confiança e constante estímulo 


\section{Agradecimentos}

Ao meu orientador Professor Adrian Sgarbi, pelo incentivo e parceria para a realização deste trabalho.

Ao Programa de pós-graduação de Direito da PUC-Rio pelos auxílios concedidos, sem os quais este trabalho não poderia ter sido realizado.

À Faculdade DOCTUM de Juiz de Fora, pela iniciativa do MINTER e o constante esforço pela qualidade do Mestrado, sem os quais meu sonho não seria possível.

Aos meus Pais, sempre incentivadores incondicionais em minha vida.

Aos meus colegas da PUC-Rio.

Aos Professores que participaram da Comissão examinadora.

Ao Rapha, Isabel e demais familiares e a todos os amigos que de uma forma ou de outra me estimularam ou me ajudaram.

Ao meu amor Juliana. 


\section{Resumo}

Pereira, Matheus Bevilacqua Campelo; Sgarbi, Adrian. O Positivismo conceitual de Hans Kelsen e o Neojusnaturalismo finissiano: um debate em torno da Justiça. Rio de Janeiro, 2010. 129p Dissertação de Mestrado. Departamento de Direito da Pontifícia Universidade Católica do Rio de Janeiro.

A presente dissertação pretende contrapor o direito natural de John Finnis ao positivismo jurídico de Hans Kelsen, mais precisamente quanto às considerações desses autores em torno da discussão sobre a Justiça, conforme as razões defendidas pelas duas teorias. O foco de nossa abordagem, desse modo, se volta ao positivismo conceitual de Kelsen, ligado às fontes do Direito, onde é inadmitido valorar a proposição normativa como justa ou injusta, bem como ao neojusnaturalismo de Finnis, que desenvolve uma metodologia densa em torno da moral para demonstrar que o Positivismo Jurídico só poderá ser apto a realizar uma lúcida descrição do Direito, caso se sirva dos dogmas previstos em sua teoria. Como consequência dessa incursão, nosso objetivo também será o de demonstrar que a realidade jurídica impõe a inegável constatação de que ambas as vertentes do direito se aproximam em vários pontos, podendo-se em alguns momentos sustentar que a alegada dicotomia está de fato rompida.

\section{Palavras-chave}

Positivismo jurídico; direito natural; Hans Kelsen; John Finnis; leis injustas; justiça. 


\section{Abstract}

Pereira, Matheus Bevilacqua Campelo. Sgarbi, Adrian (advisor). The conceptual positivismo of Hans Kelsen and Neojusnaturalismo finissiano: a debate on Justice. Rio de Janeiro, 2010. 129p MSc Dissertation - Departamento de Direito, Pontifícia Universidade Católica do Rio de Janeiro.

This dissertation aims to counteract the natural right of Jonh Finnis with legal positivism of Hans Kelsen, more precisely as the considerations of these authors concerning the discussion about justice, as the reasons put forward by the two theories. The focus of our approach thus turns to the conceptual positivism of Kelsen, connected to the sources of law, where it is not admitted appraising the normative proposition as just or unjust, as well as the neojusnaturalismo of Finnis, who develops a methodology dense around of morality, to show that legal positivism only be able to perform a lucid description of the law, if it serves the tenets laid down in his theory. As a result of this incursion, our goal is also to demonstrate that legal reality requires the undeniable fact that both strands of the right approach at various points, and you may at times claim that the alleged dichotomy is indeed broken.

\section{Keywords}

Legal positivism; natural Law; Hans Kelsen; unjust laws; justice. 


\section{Sumário}

1. Introdução

2. A teoria do direito natural de John Mitchell Finnis 15

2.1. Os valores básicos 20

2.1.1. O conhecimento 27

2.1.2. A vida 29

2.1.3. O jogo 33

2.1.4. Experiência estética 35

2.1.5. A sociabilidade (amizade) 36

2.1.6. A religião 40

2.1.7. A razoabilidade prática 40

2.1.7.1. Um plano coerente de vida 43

2.1.7.2. Sem preferência arbitrária por valores 44

2.1.7.3. Sem preferências arbitrárias por pessoas 45

2.1.7.4. Desprendimento e compromisso 46

2.1.7.5. A relevância (limitada) das consequências: eficiência dentro dos limites do bom senso 47

2.1.7.6. Respeito por cada valor básico em cada ato 48

2.1.7.7. O requisito do bem comum 49

2.1.7.8. A Justiça Geral - Sua Importante Contribuição para o "Bem Comum" 50

2.1.7.8.1. A Justiça Distributiva - Como o "Bem Comum" pode ser materialmente atingido? 52

2.1.7.8.2. A justiça comutativa - Sua referência às relações intersubjetivas $\quad 57$

2.1.7.9. Seguindo os ditames da própria consciência 58

2.2. Conclusão 59

2.3. As "Leis injustas" 60

2.3.1. Primeiros aspectos 60 
2.3.2. A lei como um apelo à razão

2.3.3. O Estado de Direito como mais um requisito à justiça

2.3.3.1. As características formais da ordem jurídica e as aspirações do Estado de Direito

2.3.4. A derivação da lei positiva da lei natural 69

2.3.5. Leis injustas não são leis? 73

2.4. Conclusão 80

3. O jusnaturalismo segundo Hans Kelsen 84

3.1. O positivismo jurídico de Hans Kelsen 86

3.2. Direito e Natureza 87

3.3. Princípio da Imputação 87

3.4. A Fundamentação do Direito Positivo 89

3.5. A difícil fundamentação do Direito Natural aos olhos de Kelsen

3.6. Possível fundamentação da validade do Direito positivo segundo a doutrina jusnaturalista e segundo a Teoria Pura do Direito

3.7. Tentativa de fundamentar o Direito natural na natureza humana

3.8. Tentativa de fundamentar o Direito natural como Direito racional

4. A interpretação do Direito em Kelsen: a revelação da moral

4.1. A interpretação jurídica realizada pelos órgãos judiciais como decorrente de um processo escalonado cognoscitivo

4.2. A moral em Kelsen: sua influência e relevância na criação do Direito pelas decisões judiciais

5. Conclusão 
5.1.1. A positivação dos Direitos naturais

5.1.2. A dicotomia entre o positivismo e o Direito natural: uma versão dramatizada e equivocada?

6. Referências Bibliográficas 